\title{
Contexto
}

\section{De una ciencia ideológica y opresora hacia la co-construcción de una ciencia emergente y ética}

\author{
Martha Elena Martínez Vélez* \\ Nuestra historia es no solamente de las conquistas de la razón, \\ sino también la de sus cegueras, sus extravíos y su \\ autodestrucción. \\ E. Morin (1998)
}

\section{Resumen}

El propósito de este escrito es reflexionar sobre algunas características que fueron configurando el surgimiento de la ciencia moderna, su importancia en la forma como los seres humanos pensaban la realidad. Asimismo, se introduce, por un lado, una mirada crítica a la ideología en la ciencia, entendida esta como un mecanismo de control de las sociedades dominantes, $y$, por el otro, la necesidad de (re)pensar y reflexionar(se) la lógica científica por fuera de una perspectiva cientificista, esto es, pensar, ejercer y, sobre todo, vivir la ciencia con sentido ético. Este cambio de horizonte lleva indiscutiblemente a co-construir otras lógicas de pensamiento a la hora de comprender y problematizar los asuntos humanos.

Palabras clave: modernidad, ciencia moderna, ciencia emergente, paradigma.

* Psicóloga Clínica y Magíster en Psicología de la Universidad de San Buenaventura. Docente universitaria.

marthemv@yahoo.es 


\title{
Contexto wartiner, M.
}

\section{From an ideological and oppressive science \\ towards co-constructing an ethical \\ and emergent science}

\begin{abstract}
This paper intends to discuss some features that have been shaping the emergence of modern science, its importance in the way human beings conceive reality. Also, on the one side, a critical view on ideology in science is introduced, where ideology is understood as a mechanism of control from domineering societies, and on the other side, we discuss the need to (re) think and reflect (himself/ herself) about scientific logic outside a scientificistic perspective, that is, thinking, practicing, and, most of all, living science with a sense of ethics. This change in the horizon will undoubtedly lead to co-constructing other forms of logical thinking when the time comes to understand and problematize human affairs.
\end{abstract}

Key words: modernity, modern science, emerging science, paradigm.

\section{Dès une science idéologique et oppressive vers la co-construction d'une science émergente et éthique}

\section{Résumé}

Le but de cet écrit est de réfléchir sur quelques caractéristiques ayant contribué à l'éclosion de la science moderne et aussi sur son importance dans la manière dont les êtres humains pensaient la réalité. Par ailleurs, il s'agit d'un côté de porter un regard critique sur l'idéologie de la science selon lequel cette dernière constitue un mécanisme de contrôle des sociétés dominatrices. D'un autre côté, nous mettons l'accent sur le besoin de (re)penser et de réfléchir sur la logique scientifique en dehors de la perspective scientiste. Ce qui implique de penser, de pratiquer et surtout de vivre la science selon un critère éthique. Ce changement de perspective amène incontestablement à co-construire d'autres logiques de la pensée lorsqu'il est question de comprendre et de problématiser l'homme.

Mots-clés: modernité, science moderne, science émergente, paradigme. 


\section{Introducción}

La primera parte de este escrito se abre con una introducción breve del contexto histórico, social, político y económico, en el cual va emergiendo y se va configurando la ciencia moderna, que tiene su epicentro en el Viejo Continente. Luego el psicoanalista Néstor A. Braunstein, el filósofo francés Michel Foucault y el epistemólogo austríaco Paul Feyerabend, nos introducen en una mirada reflexiva y crítica al interior de la ciencia moderna; ellos develan con sus fundamentos que la ciencia está permeada por intereses e ideologías de las sociedades dominantes, que contribuyen a la opresión y a la destrucción del hombre. Asimismo, acompañan esta discusión el sociólogo e historiador estadounidense Immanuel Wallerstein y el psicólogo colombiano Juan Diego Lopera quienes, siguiendo el camino de la reflexión del quehacer científico, abogan a favor de la ciencia y no del cientificismo, esto es, comprender la ciencia como una praxis ética del vivir. Por último, se analizan otras lógicas del pensamiento científico: la ciencia emergente de los paradigmas cualitativos y la ciencia de la complejidad de Edgar Morin.

\section{Contextualización de la modernidad: surgimiento de la ciencia}

Sucintamente, la modernidad, de acuerdo con Obiols y Di Segni (2006), es un período histórico que se fue gestando principalmente en las ciudades comerciales de la baja Edad Media y se configuró durante los siglos XVII y XVIII, y con él surgieron cambios sociales, económicos, políticos, religiosos y educativos.

Como consecuencia de las expansiones, expediciones y colonizaciones de Europa al nuevo continente, ocurrieron cambios y transformaciones sociales, se desplazó el orden social del feudalismo y apareció una nueva forma económica: el mercado. “El nacimiento del mercado — dirá el maestro Uricoechea (2000, p. 48)—, como institución rectora del intercambio y del principio de asignación de los recursos materiales y simbólicos", es revolucionario en cuanto no solamente se realizan en él intercambios netamente monetarios, sino que también se da la distribución de recursos relacionados con una visión antropológica, como la honra, la autoridad, el poder, la capacidad económica, entre otras, lo que permite entonces, de acuerdo con el autor, un principio de organización social fundamentado en la sociabilidad e integración social. Al tiempo que florece el mercado, se va liquidando de forma pacífica la vida institucional de las sociedades feudales y patrimoniales, y se deja atrás el orden feudal que había prevalecido durante la Edad Media. 


\section{Contexto wartiner, M.}

En el ámbito político, a finales del siglo XVII, nace la idea del Estado-Nación, deudora de la Declaración de Virginia (Carta de Derechos Humanos de 1776) y la Revolución Francesa. Con el Estado-Nación son los ciudadanos los verdaderos actores políticos de la dinámica social (Parada, 2009). Gracias a la Revolución Francesa pasamos de un sujeto subyugado por un régimen feudalista a un sujeto con derechos, a un ciudadano libre y autónomo, dicho de otra forma, a una noción de hombre universal.

La modernidad también devela los dogmas religiosos. Se produce la Reforma Protestante que cuestiona el principio de pobreza y exalta el valor del trabajo, lo que da pie al desarrollo del capitalismo y a un afán de adquirir riquezas.

Es indudable que la Modernidad como período histórico trajo significativos cambios y transformaciones en la vida social, política, económica y religiosa, desde luego la revolución del pensamiento durante esta época está íntimamente relacionada con lo que se denomina la Revolución Científica (XVII) y el movimiento intelectual de la Ilustración (VXIII). Veamos de forma sucinta estos acontecimientos históricos.

Durante el siglo XVI se gestaron los grandes descubrimientos y con ellos nuevas formas de comprender y explicar el mundo: Nicolás Copérnico (1473-1543) y Johannes Kepler (1571-1630) son los iniciadores de una comprensión de los fenómenos de la naturaleza fundamentada en la observación y matematización, sus aportes fueron, respectivamente, el heliocentrismo y las leyes del movimiento planetario. Galileo Galilei (1546-1642) contribuyó a la física y al método científico e Isaac Newton (1642-1727) cerró este período grandioso unificando “en una bella teoría matemática la mecánica terrestre y la celeste”. (García, 1996, p. 47)

Lo significativo de la revolución científica, a mi modo de ver, es que se pasa de una concepción de hombre y de universo regida por mandatos divinos, a una explicación objetiva, matematizada y demostrable, en otras palabras, nace la idea positivista de la ciencia como un ente de poder globalizante y universal poseedor de la verdad absoluta. Y por tanto el ser humano se libera de la divinidad, pero queda sometido a las leyes de la naturaleza y a las explicaciones de la ciencia.

Otro de los movimientos importantes de la Modernidad que contribuyó a los cambios y transformaciones de la sociedad europea, fue el movimiento liderado por los filósofos durante el siglo XVIII: la Ilustración. Estos filósofos soñaron con un mundo mejor, y a partir de esta utopía plantearon el ideal de felicidad y progreso apoyados en el auge no solamente de la razón sino también de la 
nueva ciencia, concebían el conocimiento liberador, pues a mayor entendimiento mayor virtud y felicidad entre quienes compartían el saber. Para lograr la difusión del conocimiento, los ilustrados centraron su atención en la educación, especialmente en la escuela y los libros. La educación debía ampliarse a todos los sectores sociales, de este modo, ciencia y educación brindaban el sueño de lograr un mundo mejor y garantizaban el crecimiento material y espiritual (Obiols y Di Segni, 2006). De aquí se deduce entonces que el ser humano no puede encontrar otras vías de conocimiento sino a través de la razón, de la ciencia que impregnaba la educación y los libros.

Este es el panorama de la Modernidad sus cambios y transformaciones, quizás los más significativos tienen que ver tanto con el nacimiento de las instituciones y los Estados-naciones como con el surgimiento de la ciencia, pues en ella se depositaron el ideal de progreso y el bienestar del hombre. Llegados a este punto, la ciencia concebida como progreso y bienestar, encontramos que no pocos autores piensan lo contrario: que la ciencia tal como fue pensada en el proyecto moderno se fue alejando de estos principios, y se fue transformando en una ciencia opresora, destructora y cientificista.

\section{La ciencia: de la ideología opresora y cientificista a una ciencia ética y liberadora}

Bajo la mirada de Néstor Braunstein (Braunstein et al., 2001), la ciencia es opresora y está al servicio de unos pocos, es utilizada por la ideología, entendida esta como un mecanismo de control y de poder de las clases dominantes (burguesía/ religión) para justificar y legimitizar su opresión en lo social. Nicolás Cópernico, Giordano Bruno y Galileo Galilei son ejemplos vivos de este control social. Al desplazar Copérnico al hombre de la visión geocéntrica de Ptolomeo, rompía con una visión teológica y cuestionaba la omnipotencia de Dios, motivo por el cual su libro estuvo por mas de 300 años en el Index de los libros prohibidos de la Iglesia, fue asimismo acusado de herejía y llevado a la hoguera; Galileo Galilei fue obligado por el Santo Oficio a retractarse públicamente de las ideas defendidas de Copérnico. Cuando la ciencia quiere disputar el poder con el saber religioso, el poder religioso se siente amenazado en sus cimientos. La historia de la ciencia no puede entenderse como una disputa histórica por el poder contra la Iglesia o el saber religioso, lo que se defienden son ideologías de poder, y cada una tiene pretensiones de verdad absoluta.

Desde otro lugar, la aceptación de la ciencia, Braunstein plantea que el desarrollo de las ciencias ha sido aceptado sin objeciones pero no por ello sin ideología, 


\section{Conterto Matrine, M.}

es el caso de los químicos Antoine Lavoisier (1743-1794) y John Dalton (17661844), pues sus descubrimientos no representaban peligro alguno para quienes pertenecían a la clase dominante, por el contrario, servían a sus propios intereses económicos y políticos; por ejemplo, la creación de las tinturas contribuía a la fabricación de los tejidos y el invento de los explosivos servía para la colonización de territorios, es decir, expansión de dominio y poder.

Además de señalar la ideología de la ciencia moderna en sus inicios, como lo vimos en los párrafo anteriores, Braunstein nos lleva también al siglo XIX, cuando aparece la teoría del origen de las especies de Charles Darwin (1809-1882), que causa revuelo en el orden establecido y se cuestiona de nuevo la omnipotencia de Dios frente a la creación del hombre y las criaturas; era necesario entonces oprimir de nuevo el conocimiento reciente.

Estos acontecimientos históricos llevan a Braunstein a fundamentar que la ciencia actuará según las necesidades de la ideología, pero este panorama, que aparentemente se torna oscuro y desesperanzador, se desvanece cuando el mismo autor propone una salida, una posibilidad de desligar la ciencia de las ideologías opresoras. La salida propuesta es generar movimientos liberadores con respecto a las estructuras de poder desde la misma ciencia, es decir, de quienes somos responsables de construir ciencia (teorías) o reflexionar sobre ella, y acá quiero llamar la atención del lector, pues la ciencia pasa de ser un concepto abstracto para transformarse ante todo en una praxis ejercida por seres humanos concretos y reales. En palabras de este autor:

Desenmascarar la opresión social y la sujetación individual significa plantear automáticamente la cuestión de la abolición de las clases privilegiadas y la cuestión de la desujetación individual. Estos planteamientos teóricos no transforman, de por sí, la realidad del mundo. Pero ellos llevan, indefectiblemente, a orientar sobre la base de teorías científicas a las prácticas de transformación de las estructuras. (Braunstein et al., 2001, p. 18)

En la misma línea de pensamiento reflexivo de Braunstein frente a la ideología de la ciencia moderna como un ente de conocimiento de poder, globalizante y unitario, se encuentran Michel Foucault y Paul Feyerabend.

Foucault afirmaba que la ciencia utiliza el lenguaje como artificio para crear sus teorías, por tanto al utilizarlo crea realidades sobre las cuales tiene dominio y poder. La genealogía, fundamenta este autor, es un camino para develar los hilos invisibles del poder de la ciencia: 
La genealogía sería entonces, respecto y en contra de los proyectos de una inscripción de los saberes en la jerarquía de los poderes propios de la ciencia, una especie de tentativa de liberar de la sujeción a los saberes históricos, es decir, hacerlos capaces de oposición y de lucha contra la coerción de un discurso teórico, unitario, formal y cientifico. La reactivación de los saberes locales -menores, diría Deleuze - contra la jerarquización cientifica del conocimiento y sus efectos intrínsecos de poder: ése es el proyecto de estas genealogías en desorden y fragmentarias. (1996, p. 20)

Es importante aclarar lo que este autor piensa de la ciencia, no está a favor de la ignorancia o el no saber, su crítica y reflexión están enmarcadas en los intereses del poder que se ejerce a través de la ciencia en las instituciones y en la sociedad en general, desconociendo los acontecimientos sociohistóricos de quienes hacen parte de ella. Para este autor, la genealogía es un posible método para el análisis de las discursividades locales, sería la táctica que, a través de esos análisis, dinamizaría los saberes y los liberaría de quedar atrapados en el poder; dicho de otra forma, la ciencia moderna con su método experimental daría paso a otras alternativas del conocimiento igualmente válidas.

Por su parte, el pensador Feyerabend, en consonancia con la posición de Foucault, interroga también la ideología de la ciencia. Una ideología, para este autor, significa que "está compuesta por un conjunto de teorías junto con un método y una perspectiva filosófica general, y así la ciencia, ligada a métodos y proveedora de teorías, se constituye en la médula ideológica de la modernidad" (citado por Toledo, 1998, p. 8), por tanto, la ciencia también va demarcando una forma de vida y explicación del mundo, negando y aniquilando otras formas, comprensiones y diversidades del mundo de la vida, diferentes a la visión eurocentrista. Feyerabend señala la indiferencia de los europeos a la hora de comprender nuevas culturas, "no hubo ninguna comparación objetiva de métodos y resultados. Solo hubo colonización y represión de las tribus y naciones colonizadas". (citado por Toledo, 1998, p. 8)

Por eso el eurocentrismo y la racionalidad moderna entran en la mira de críticas y reflexiones, pues a nombre de la razón y el conocimiento se cometieron atrocidades humanas. Lo pensado en la modernidad, el desarrollo, el bienestar y la felicidad, se desmiente al mirar las otras caras de la realidad: por un lado, la destrucción, el dolor y la desolación que dejaron el domino y la conquista de otras culturas, los negros, los indígenas y las mujeres son el reflejo de esto, y por el otro, el campamento de concentración de Auschwitz. Toledo nos recuerda el genocidio judío y el sufrimiento de los gitanos: 


\section{Contexto Martinez, M.}

(...) Auschwitz reclamaría ser admitida entre las consecuencias de la racionalidad cientifica; de hecho muchos experimentos de injertos e inoculación de enfermedades que utilizaron a niños judios en el rol de conejillos de indias obtuvieron resultados nada despreciables para la medicina, asimismo la metódica eficiencia del exterminio de judios y gitanos fue resultado de una planificación racional. Algo parecido puede decirse de la hecatombe ecológica de nuestra época que tiene su contrapunto en el vertiginoso desarrollo industrial con su concomitante necesidad de insumos e inevitable producción de desechos. Así, la esperanza de que el progreso sería la consecuencia (útil) obvia de la ciencia ha sido sometida a prueba y refutada. (Toledo, $p$. 6)

Ante estos señalamientos de la ciencia moderna, Feyerabend se aleja de los presupuestos de esta ciencia para proponer una ciencia cuyos fundamentos están en la etnografía cognitiva, el contexto histórico y sociocultural será el que guíe y fundamente las nuevas formas de pensar y comprender el mundo, ya no es una realidad objetiva y única, sino que pueden coexistir múltiples realidades e igualmente válidas desde un determinado contexto. La ciencia de los hechos pasa entonces a la ciencia de los actos sociales o humanos, su criterio de validez dependerá del contexto histórico y los acuerdos sociales.

En las ciencias humanas se reivindican los saberes primitivos, simbólicos y religiosos, formas de conocer similares a las que Foucault (1979) plantea en la pirámide de los umbrales del saber. Si bien es cierto, el hombre primitivo utilizó el pensamiento mítico, mágico y sobrenatural como una forma de comprender y explicar el principio de la vida, esto no fue obstáculo para avanzar en otras áreas del conocimiento como la matemática, la medicina natural, la astronomía, la agronomía y la construcción. Sumeria, Egipto, Grecia, Perú y México, entre otras, son ejemplos de antiguas y grandes civilizaciones. El retorno a otros saberes primitivos no solamente le devuelve al ser humano su naturaleza mítica-espiritual escindida durante la Edad Media y la Modernidad, sino también que la razón, como plantea Feyerabend, "no es la única forma de inteligibilidad y tampoco la última: La ciencia es una de las muchas formas de pensamiento que el hombre ha desarrollado y no necesariamente la mejor". (citado por Toledo, 1998, p. 6)

Por el lado de quienes defienden la ciencia y no el cientificismo citamos a Immanuel Wallerstein (2004), y con planteamientos muy similares a los de Foucault y Braunstein. El cientificismo, de acuerdo con Wallerstein, es una concepción de ciencia rígida, catalizadora y ajena a las realidades subjetivas, crea teorías y resultados de acuerdo a los propios intereses de quienes investigan. Pero dejemos que sea el mismo autor quien defina dicho concepto: 
(...) me refiero a la idea de que la ciencia es desinteresada y extrasocial, que sus enunciados de verdad [se] sostienen por símismos sin apoyarse en afirmaciones filosóficas y que la ciencia representa la única forma legítima del saber. En mi opinión, los escépticos de los últimos años, que en muchos casos solo recurrieron a críticas que ya existían hacía mucho tiempo, han demostrado la debilidad lógica del cientificismo. En la medida en que los científicos se pongan a la defensiva para proteger al cientificismo, solo lograrán quitarle la legitimidad a la ciencia. $(2004, p$. 19)

Es importante centrar la atención en tres palabras que este autor utiliza al referirse al cientificismo: desinteresada, extrasocial y filosofia, pues, a partir de ellas fundamentará un concepto de ciencia que vele por el bien de las personas, sus particularidades, subjetividades e intersubjetividades, y lo más importante aún, invita a quienes hacen ciencia a reflexionar sobre su lugar y su condición humana.

De lo anterior se puede deducir que los hombres y mujeres que hacen ciencia pueden estar a favor o en contra de las ideologías dominantes, pueden generar conocimiento opresor o liberador; de allí la importancia de la diferenciación que establece Ramírez (citado en Lopera et al., 2007, p. 18) entre el científico y el hombre de ciencia. El primero está relacionado con un científico ético, cuyo conocimiento está al servicio del pensamiento liberador y por lo tanto generador de transformaciones sociales, un científico es la esperanza de que el conocimiento no caiga en el abismo y en la oscuridad, para ello se requieren características personales como la capacidad de reflexión, crítica y aprendizaje de los errores y horrores de la misma ciencia y del hombre. El hombre de ciencia, por el contrario, carece de sensibilidad social, pues el conocimiento está por encima de los valores, de la ética y la subjetividad.

Desde la perspectiva del hombre de ciencia, la filosofía, la ciencia y la técnica deben caminar y aprender a conocer sus limitaciones, alcances y riesgos. Solo cuando se tiene conciencia de la imperfección humana se emprende el camino hacia la humanización, nos preguntamos no solamente por nuestro lugar en el mundo, sino por los principios que rigen nuestro quehacer investigativo, en otras palabras, nuestra ética.

\section{Una ciencia emergente: necesidad de (re)pensarnos diferente y en contexto}

Una vez se ha comprendido la ciencia moderna, su ideología y la necesidad de otras lógicas de pensamiento que permitan, por un lado, desenmascarar, develar y abolir los hilos del poder opresor en vías de la liberación del sujeto y, por el 


\section{Contexto wartiner, M.}

otro, negar el uso del método científico como simple instrumento de aplicación, no son menos importantes otras formas de construir conocimiento científico que, por supuesto, tienen sus orígenes en la crítica de la ciencia objetiva y el ideal de la racionalidad moderna.

Existen otras formas de conocimiento, tal como la planteada por el filósofo Feyerabend, la ciencia de la etnografía cognitiva, cuyo fundamento está en el contexto socio-histórico-cultural. Allí convergen diversos estilos cognitivos, es decir, formas de sentir, pensar y comprender el mundo, por lo tanto, según este filósofo, no existe un estilo cognitivo superior o inferior a otro porque no existe un metacriterio objetivo para ello, solo existe el criterio de validez, en tanto los actores sociales se relacionan y establecen significados y consensos sobre la realidad construida.

Precisamente, porque la ciencia moderna se considera reduccionista y determinista, nace la necesidad de pensar en una ciencia que se aproxime a comprender los fenómenos sociales desde la vivencia y perspectiva de los mismos actores sociales, sujetos activos, responsables y participativos, tanto de su vida cotidiana como social y cultural. Este modo de sentir, pensar y ver el mundo rompe con lo que Guba y Lincoln (2002) han denominado la "perspectiva heredada" o ciencia positivista.

Si bien los paradigmas ${ }^{1}$ de ciencia denominados emergentes, cualitativos o alternativos, entre ellos, el constructivismo, la teoría crítica y otras posiciones e ideologías similares, como la investigación acción participativa y el construccionismo social (Guba y Lincoln, 2002; Martínez, 1997; Valles, 1999; Gergen, 2006), tienen sus divergencias en cuanto al uso de la metodología y sus fundamentos teóricos, comparten, de acuerdo con Ibáñez (2001, p. 84), una serie de presupuestos comunes:

(...) por un antipositivismo contundente, por el reconocimiento del ser humano como "agente" parcialmente autodeterminado, por una sensibilidad particular hacia el carácter histórico o "construido" de las realidades psicosociales, y por la centración sobre la importancia que representa el lenguaje y la significación, por la atención hacia la relacionalidad práctica, por el interés hacia los procesos concretos de la vida cotidiana y por la conciencia de las implicaciones de todo tipo que se desprenden a partir de la propia reflexibilidad del conocimiento.

1. Comparto con Guba y Lincoln su definición de paradigma: sistema básico de creencias o visiones del mundo que guía al investigador, ya no sólo a elegir los métodos, sino en formas que son ontológicas y epistemológicas. 
La ciencia emergente es la necesidad de (re)pensarnos distintos en nuestra condición de humanidad, de comprender los fenómenos psicosociales desde las subjetividades e intersubjetividades, por lo tanto, la ciencia emergente es una necesidad de construir un nuevo paradigma de ciencia, ya el devenir histórico de la ciencia moderna nos ha develado que los hechos separados de los valores, lo que es y debería ser, nos han llevado, como lo plantea Martínez, a un "progreso destructor", por ello la ciencia emergente no aspira a ser objetiva, precisamente por lo sensible de su objeto de estudio: el hombre. La siguiente cita ilustra la sensatez de esta posición:

(...) en el nuevo paradigma, tendrá muy presente que las ciencias humanas nunca podrán ser objetivas, porque nunca se podrá objetivizar a su objeto de estudio, que es el científico mismo, aun en el acto de hacer ciencia. Si, como afirma Kant, la ciencia es un producto del hombre, ésta nunca podrá dar razón plena de él. (Martínez, 1996, p. 19)

Paralelamente a estos críticos de la racionalidad moderna, que ven la necesidad de construir otro paradigma de ciencia sensible a los fenómenos sociales, se encuentra desde otro lugar el polifacético francés Edgar Morin, con su lógica de la complejidad. Si bien los presupuestos filosóficos y epistemológicos de este paradigma difieren de la concepción de los paradigmas emergentes descritos en el párrafo anterior, tienen en común la comprensión de un sujeto por fuera de la ciencia moderna, de la racionalidad instrumental, un sujeto que no sea ajeno a su propio devenir histórico.

En la lógica de la complejidad se plantea, grosso modo, la diversidad, la interacción y el azar en una interrelación sistémica (el todo y sus partes, sus partes y el todo). Estos elementos (diversidad, interacción y azar), al igual que el orden, el caos y, por qué no, la sensibilidad, conducen y recuerdan otras vías de comprensión de lo propiamente humano (universo, naturaleza, Homo sapiens sapiens, Homo demens, cultura, poesía y mito). Para ello, Morin propone una segunda "nueva alianza", entre ciencia y una filosofía propiamente reflexiva. Esta nueva "alianza", bajo mi perspectiva, se puede comprender como guardiana de la supervivencia humana, es decir, entre el Homo sapiens sapiens y el Homo demens, pues en la condición humana habitan tanto la creatividad y la armonía (Homo sapiens sapiens) como la desmesura, la demencia y las pasiones (Homo demens). Este último ha sido protagonista de horrores, miedos y dolores a lo largo del devenir humano, realidad no ajena a Morin, tanto por su propia experiencia política y militante contra el nazismo en Alemania durante la Segunda Guerra mundial como por su formación académica. Por ello, para este gran pensador la razón se comprende como conquista, ceguera y destrucción. Invito entonces 


\section{Contexto Martinez, M.}

al autor a que describa en qué consiste esta nueva "alianza", una alianza de esperanza y esperanzadora para quienes todavía creemos en la humanización de la ciencia y, por supuesto, en una ciencia ética y sensible.

(...) la verdadera racionalidad es de naturaleza dialógica: es el diálogo entre lo lógico y lo empírico, diálogo que conlleva en su seno el diálogo entre lo racional y lo irracionable. (...) Esta racionalidad, que conlleva en sí misma la potencialidad de autocrítica y de autosuperación, constituye un tesoro vital para el espíritu humano. Pero para salvar y desarrollar la racionalidad, nos hace falta hacerla capaz de afrontar la complejidad, es decir, la multidimensionalidad, la incertidumbre, la contradicción, nos hace falta una segunda "nueva Alianza", esta vez, entre el modo de conocimiento científico, que vía observaciones, verificaciones, "falsaciones", mira hacia la objetividad, y el modo de conocimiento filosófico, propiamente reflexivo, que mira sobre todo a elucidar la relación entre el sujeto y el objeto de conocimiento. (1998, p. 33)

A modo de conclusión, pensar la ciencia desde otras lógicas de conocimiento no es otra cosa que pensar(la) como un ejercicio del vivir ético, intelectual y reflexivo, en cuanto somos los seres humanos reales y concretos quienes cocreamos, co-construimos y deconstruimos constructos, y por tanto formas de explicación y comprensión del mundo. A diferencia de la racionalidad moderna, el nuevo paradigma ciencia, con su diversidad de lógicas de pensamiento, le apuesta a una ciencia humanizante, dicho de otra forma, una ciencia al servicio de la humanidad y por la humanidad, sensible y cuidadora del ser humano y su entorno. Es una ciencia de la esperanza frente al temor de la condición posmoderna, la autodestrucción humana o, como dice Morin (1974, p. 741 citado por Solana, 1998), al "homo, que es a la vez homo sapiens-demens", configurado este último por la desmesura, sus pasiones y la destrucción humana y ecológica.

\section{Referencias bibliográficas}

Braunstein, N., Pasternac, M., Benedito, G. y Saal, F. (2001). Psicología: Ideología y ciencia. México: Siglo Veintiuno.

Foucault, M. (1996). Genealogía del racismo. La Plata: Editorial Altamira. (1979). La arqueología del saber. México: Siglo XXI Editores

García, L. (1996). El desarrollo de los conceptos psicológicos. Una

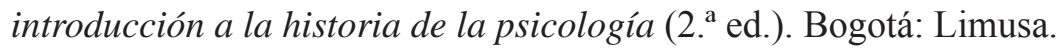


Gergen, K. (2006). Construir la realidad. El futuro de la psicoterapia. Barcelona: Paidós.

Guba, E. y Lincoln Y. (2002). Paradigmas en competencia en investigación cualitativa. En C. Denman y J. Haro (comps.), Por los rincones. Antología de los métodos cualitativos en la investigación social (pp. 113-145). México, Hermosillo: El Colegio de Sonora.

Ibáñez, T. (2001). Las corrientes alternativas. En Bernardo Jaramillo (comp.). Psicología Social Construccionista. Guadalajara: Universidad de Guadalajara.

Lopera, J. N. et al. (2007). El método científico. Textos guías en el marco de la investigación en curso El método analítico, aprobada por el Comité para el Desarrollo de la Investigación — CODI— de la Universidad de Antioquia.

Martínez, M. (1997). Comportamiento humano. Nuevos métodos de investigación. México: Trillas.

Morin, E. (1998). La Relación ántropo-bio-cósmica. En El Pensamiento complejo y la familia. Memorias del II Congrego Latinoamericano de Familia siglo XXI. Medellín: Comité Interinstitucional de Familia - CIF-.

Obiols G. y Di Segni S. (2006). Adolescencia, posmodernidad y escuela. La crisis de la enseñanza media. Buenos Aires: Novedades Educativas.

Parada, C. (2009). Hacia un nuevo concepto de ciudadanía global. Via Iuris, 7, 98-111. Recuperadodehttp://dialnet.unirioja.es/servlet/articulo? codigo=3293442.

Solana, J. (1998). Bioculturabilidad y homo demens. Dos jalones de la antropología compleja. En El Pensamiento complejo y la familia. Memorias del II Congrego Latinoamericano de Familia Siglo XXI. Medellín: Comité Interinstitucional de Familia - CIF-.

Toledo, N. (1998). La epistemología según Feyerabend. Cinta de Moebio, 4. Recuperado de http://www.facso.uchile.cl/publicaciones/moebio/04/feye.htm

Uricoechea, F. (2000). Lo público: historia y estructura. Trabajo presentado en el Seminario Visiones de lo público. Medellín, Universidad Nacional.

Valles, M. (1999). Técnicas Cualitativas de Investigación Social. Reflexión Metodológica y Práctica Profesional. Madrid: Síntesis, S.A.

Wallerstein, I. (2004). Las incertidumbres del saber. Barcelona: Gedisa. 